\title{
The field factor: towards a metric for academic institutions
}

\author{
Ulf Sandström and Erik Sandström
}

\begin{abstract}
We present a new model for performance-related funding of universities in Sweden. The model is based on number of papers in international scientific journals, but relies on an estimation of fieldadjusted production per scientific/technological area. Author counts are based on potential authors using the Waring distribution for 34 areas of science (Schubert and Braun, 1992). We apply this model to the Swedish university system and illustrate with the reallocations that would follow from a complete implementation. Next, we test the accuracy of the method using publication data from six Swedish universities and four Norwegian universities. In conclusion we discuss advantages and drawbacks with the method.
\end{abstract}

$\mathrm{H}$ OW BEST TO ASSESS research performance is a matter of great concern. Performance-related funding, or formula-based funding, has been under discussion for several years, and metrics have come to be seen as an alternative. The UK RAE system has traditionally leaned on peer-review procedures, but is now moving towards a metrics-based system. Norway has introduced a framework for counting all scientific publications, crediting them to institutions based on fractions of publications.

The Norwegian model, introduced in 2005, uses a weighting of publications in two dimensions: first, according to different publication channels (articles in ISSN journals, chapters in ISBN books, and ISBN books) and, second, according to level of quality of the publication (normal and high). Approximately $80-90 \%$ of all university publications is covered by the documentation system built up for the purpose of formula funding (Sivertsen, 2006).

Instead of journal impact the Swedish discussion has focused on actual citations as a proxy for research quality. Therefore, the field-normalized citation rate, which was introduced by the Budapest group (Braun et al, 1990; Schubert and Braun, 1996)

Ulf Sandström is at Linköping University, ISAK, SE-581 83 Linköping, Sweden; E-mail: ulf.sandstrom@liu.se; URL: www.forskningspolitik.se. Erik Sandström is at Gothenburg University, SE-405 30, Gothenburg, Sweden. and applied by the Leiden group (Van Raan, 1996), plays a prominent role in the debate. Many Swedish universities express, in their comments to the official report (see below) their preference for evaluation of performance using field-normalized indicators.

This Swedish Government has announced its new Research and Innovation Bill (Prop. 2008/09:50), by which $5 \%$ of direct funding to universities will be based on a publication/citation indicator. Universities will receive floor funding according to number of publications and rate of citations. This incentive model, based on field factors also for the productivity dimension, was first introduced by the present authors in the so-called Resources Inquiry led by Professor Dan Brändström (SOU, 2007: 81).

In the Scandinavian debate, voices have been raised asking for a field factor for academic production. Actually, this was one of the starting points for the Norwegian discussion on performance-based funding. It is well known that medical researchers tend to produce more, often shorter papers where methodology and prior knowledge is codified in citations; and engineering scientists produce less frequently and have fewer cross-references (Narin and Hamilton, 1996; Glänzel, 1996). These field differences affect both citation rates and mean number of papers per author, and the differences are to some extent explained by shifting coverage of fields in the ISI database.

Surprisingly, the productivity dimension has not been emphasized in recent debates. Rankings of 
universities, for example, the Shanghai ranking, do not take these differences into account. Also the Leiden ranking (CWTS, 2008) fails on this specific point. Through multiplication of relative citations by number of publications, universities active in the medical areas receive higher rankings, given the same citation performance, due to more frequent publishing.

Therefore, a relative productivity measure is central to the discussion of performance-based funding. If we want to use science metrics as a means for redistribution of basic funding to universities there is need for a 'field-normalized' productivity measure. In this paper we will introduce a field factor for academic production.

\section{Problem and methodology}

In the creation of field factors a major obstacle emerges: publication databases give information on the authors that are active during a given period, not all the potential authors. As the non-contributors (non-publishing authors) are unknown it is difficult to create an average publication rate per author taking all potential authors into account. But there is a proposed mathematical solution to this problem: bibliometric data can be characterized as Waring distributions (Schubert and Glänzel, 1984). With information on the distribution of author publication frequencies, an estimate of the average publication rate per researchers (contributors and noncontributors) in a given field, country or such can be computed (Telcs et al, 1985).

The approach is based in mathematical statistics and a theoretical discussion can be found in papers by Braun, Glänzel, Schubert and Telcs during the second half of the 1980s. Inspired by Irwin (1963) they showed that bibliometric data could be characterized as Waring distributions (Glänzel et al, 1984). A straight line should be obtained by plotting the truncated sample mean of these distributions (Telcs et al, 1985). By extrapolating this series to 0, the numbers of non-contributors are included. The intercept of this line is the estimated average productivity of all potential authors during a given period of time (Braun et al, 1990).

In our model this value is used as a reference value and is computed per field for Nordic data. Several successful empirical tests using similar models based on Waring distributions have been implemented (e.g. Schubert and Glänzel, 1984; Schubert and Telcs, 1986, 1989; Buxenbaum et al, 1987; Sandström and Sandström, 2007, 2008b).

When applying this model we use Web of Science data with first authors (AU) and reprint (RP) authors that have an address at a Nordic university. Homonyms and similar problems are taken care of by manual procedures. This was done for all Nordic universities (Sweden, Finland, Denmark and Norway) and the operation yielded 54,000 unique authors for the period 2003-2006.
Field delineation is an important issue. For citations the Thomson/ISI subject categories are used, but these 250 categories create too small samples when Nordic authors are used to create productivity data. There are several alternative ways of producing macro classes (e.g. SPRU classes or the Thomson ESI field categories). In this case we clustered all journals using inter-citations as proximity values (Boyack and Klavans, 2006). We chose to use the least frequent relation to distinguish, as far as possible, between basic and applied sciences. It has been shown by Rinia et al (2002) that applied sciences tend to cite back to more basic sciences, not the other way around. The clustering procedure was based on the DrL cluster algorithm (Martin et al, in preparation) and created 34 macro classes (fields). ${ }^{1}$

Fields and the distribution of papers in the Nordic countries are shown in Table 1 . The differentiation into fields is a bit more detailed than the ISI (Thomson Reuters) field definitions or the macro fields proposed by Glänzel and Schubert (2003). It seems to be an interesting alternative route to classification of journals but, of course, it is a part of the research procedure which is open to further discussion and needs validation from other investigations. Boyack and Klavans have similar methods in their world map (2006) and we refer the reader to their papers. The real test of the accuracy of the proposed 34 different fields is whether they differentiate according to relations of production, that is, the normal number of publications from an author in the field, the financing of research, the number of other activities (e.g. patenting and extra-research, societal activities).

Notable from Table 1 is that 'Medicine, internal' is the largest area and that this area has a high relative citation score. One of smallest areas is information science, which to a large extent covers library and information studies, an area that receives a very high citation score in several Nordic countries.

With the delineation of fields we can compute the normal productivity per Nordic author and field. The methodology described above was used to establish a reference value based on all Nordic universities (Sandström and Sandström, 2008a). By using the number of articles per Swedish university divided by the reference value (the field factor) we obtain the relative quantity of production performed by the university in each macro field. We name this indicator field-adjusted production (FAP). Then, simply by multiplying the specific university production score per macro class by the field-normalized citation score (NCSf or the crown indicator CPP/FCSm) we establish a combined value incorporating production and 'quality' of production. The resulting total sum represents the production from the university and should be related to the total income per university. The advantage of using this method is that universities are made comparable although they have their main activities in completely different fields of science. 


\begin{tabular}{|c|c|c|c|c|c|c|c|c|}
\hline \multirow[b]{2}{*}{ Field } & \multicolumn{4}{|c|}{ Publications (\%) } & \multicolumn{4}{|c|}{ Citations (field-normalized) } \\
\hline & Denmark & Finland & Norway & Sweden & Denmark & Finland & Norway & Sweden \\
\hline Agriculture & 4.5 & 2.5 & 2.8 & 1.6 & 1.53 & 1.50 & 1.35 & 1.44 \\
\hline Biology & 8.2 & 8.4 & 13.1 & 6.7 & 1.18 & 1.10 & 1.18 & 1.22 \\
\hline Biomolecular & 4.8 & 3.6 & 3.9 & 5.2 & 1.37 & 1.17 & 1.29 & 1.36 \\
\hline Blood & 2.3 & 2.3 & 3.2 & 2.9 & 1.04 & 0.89 & 0.88 & 1.06 \\
\hline Chemistry & 6.72 & 7.6 & 5.2 & 7.6 & 1.46 & 1.07 & 1.07 & 1.35 \\
\hline Computer Science & 3.8 & 6.1 & 4.0 & 3.9 & 1.18 & 1.03 & 0.96 & 1.05 \\
\hline Dentistry & 1.0 & 1.2 & 1.4 & 1.6 & 1.18 & 1.11 & 0.92 & 1.28 \\
\hline Ecology & 7.4 & 7.1 & 6.8 & 6.7 & 1.43 & 1.10 & 1.07 & 1.29 \\
\hline Economics & 2.1 & 1.8 & 2.8 & 2.0 & 1.05 & 0.81 & 0.96 & 1.00 \\
\hline Education & 0.3 & 0.5 & 0.4 & 0.2 & 0.54 & 1.00 & 0.91 & 0.64 \\
\hline Engineering & 1.4 & 0.6 & 2.1 & 1.6 & 1.29 & 0.88 & 1.32 & 0.95 \\
\hline Engineering math & 0.3 & 0.3 & 0.9 & 0.5 & 1.39 & 1.26 & 1.39 & 1.48 \\
\hline Environmental studies & 0.3 & 0.4 & 0.7 & 0.4 & 1.19 & 0.73 & 0.90 & 1.00 \\
\hline Ergonomics & 0.2 & 0.3 & 0.3 & 0.4 & 1.20 & 1.10 & 1.20 & 1.29 \\
\hline Geoscience & 2.0 & 0.8 & 4.4 & 1.4 & 1.19 & 0.97 & 1.25 & 1.02 \\
\hline Health care & 0.1 & 0.5 & 0.4 & 0.5 & 0.75 & 0.86 & 0.83 & 0.78 \\
\hline Humanities & 0.7 & 0.5 & 1.2 & 0.5 & 0.92 & 0.95 & 0.84 & 0.66 \\
\hline Immunology & 5.1 & 3.3 & 3.7 & 3.7 & 1.18 & 1.13 & 1.00 & 0.98 \\
\hline Information science & 0.2 & 0.2 & 0.1 & 0.1 & 2.77 & 2.08 & 1.68 & 1.51 \\
\hline Materials Science & 4.3 & 5.9 & 3.2 & 6.6 & 1.53 & 1.03 & 1.13 & 1.16 \\
\hline Mathematics & 1.0 & 1.2 & 1.2 & 1.0 & 1.20 & 1.09 & 1.24 & 1.29 \\
\hline Mechanics & 0.0 & 0.1 & 0.1 & 0.2 & 1.55 & 1.66 & 1.68 & 1.50 \\
\hline Medicine, external & 4.5 & 5.0 & 3.8 & 4.8 & 1.13 & 1.13 & 1.07 & 1.09 \\
\hline Medicine, internal & 12.8 & 12.1 & 9.2 & 11.6 & 1.28 & 1.36 & 1.22 & 1.22 \\
\hline Neuroscience & 4.8 & 6.4 & 4.9 & 5.9 & 1.11 & 1.15 & 1.10 & 1.17 \\
\hline Oncology & 4.9 & 5.3 & 5.7 & 5.9 & 1.08 & 1.06 & 0.87 & 0.91 \\
\hline Pharmacology & 1.1 & 1.5 & 0.8 & 1.3 & 0.85 & 1.15 & 0.86 & 1.11 \\
\hline Physics & 5.7 & 4.8 & 2.8 & 5.5 & 1.58 & 1.14 & 1.06 & 1.17 \\
\hline Psychology & 1.2 & 1.8 & 2.2 & 1.7 & 0.80 & 0.89 & 0.70 & 0.91 \\
\hline Public health & 2.3 & 2.5 & 2.8 & 2.9 & 1.01 & 1.08 & 0.99 & 1.03 \\
\hline Social science & 0.9 & 0.8 & 1.7 & 0.7 & 0.90 & 0.59 & 1.11 & 1.01 \\
\hline Statistics & 0.7 & 0.4 & 0.8 & 0.5 & 1.03 & 0.86 & 0.95 & 0.76 \\
\hline Surgery & 3.0 & 2.7 & 2.6 & 2.7 & 1.24 & 1.07 & 1.11 & 1.15 \\
\hline \multirow[t]{2}{*}{ Toxicology } & 1.2 & 1.4 & 1.2 & 1.4 & 1.13 & 0.89 & 1.02 & 1.13 \\
\hline & $100 \%$ & $100 \%$ & $100 \%$ & $100 \%$ & 1.26 & 1.09 & 1.06 & 1.14 \\
\hline
\end{tabular}

Source: Web of Science, January 2008

The aim of this paper is, besides introducing the method, to compare the Norwegian and Swedish models for performance-related funding. We will use Swedish and Norwegian data from the largest universities during the period 2005-2006. Publication counts according to the Norwegian model are derived from the Norwegian database $\mathrm{DBH}$ and field-adjusted production counts according to the FAP model are derived from the Norwegian FRIDA database. The categorizations into disciplines (faculty areas) were made from the names of university departments using NIFU statistics.

\section{Reallocating resources to Swedish universities}

In order to demonstrate the implementation of the field factor model we will show how it would affect the distribution of funding to Swedish universities for 2009 if used in the way proposed by us. Of course, there are other indicators and there are, as will be introduced later, also other proposals for how to build incentives for universities. Therefore, the following implementation is ours and not identical with what the Swedish Government has proposed for Swedish universities during FY 2009.

Table 2, column A, displays the number of first and reprint author papers per university during the period 2005-2007. The next column, B, contains the recalculated field-adjusted production values per university for the period 2005-2007. The effect of the field factor normalization is fairly strong, especially for area-specialized universities such as Karolinska Institute. Column C shows the fieldnormalized citation score. The period is 2004-2006 as publications should have time to gather citations for at least a year. Two-year citation windows would be preferable.

The next column, $\mathrm{D}$, holds information on the total income, direct funding plus external funding, received during the period 2005-2007. That is the input of resources that should be related to the total weighted output. Of course, there is a problem in finding out the exact timing of research: was the research done three years ago based on the resources available at that time or do we have to go further back in time, five or six years earlier? If a university 


\begin{tabular}{|c|c|c|c|c|c|c|c|}
\hline & A & B & C & D & $\mathbf{E}$ & $\mathbf{F}$ & G \\
\hline INST & $\begin{array}{l}\text { 1st and RP } \\
\text { papers } \\
(2005-07)\end{array}$ & $\begin{array}{c}\text { FAP } \\
(2005-07)\end{array}$ & NCSf & $\begin{array}{c}\text { Total income } \\
\text { MSEK } \\
(2005-07)\end{array}$ & $\begin{array}{l}\text { Column } \\
\left(B^{*} C\right) / D\end{array}$ & $\begin{array}{l}\% \text { Floor } \\
\text { funding } \\
2008\end{array}$ & $\begin{array}{c}\% \text { Proposed } \\
\text { indicator- } \\
\text { based } 2009\end{array}$ \\
\hline Lund Univ. & $4,193.5$ & $3,571.9$ & 1.17 & $3,323,473$ & 1.26 & 14.11 & 15.94 \\
\hline Uppsala Univ. & $3,743.0$ & $3,193.2$ & 1.17 & $2,853,516$ & 1.31 & 13.06 & 15.34 \\
\hline Gothenburg Univ. & $2,485.5$ & $2,291.2$ & 1.04 & $2,486,327$ & 0.96 & 12.49 & 10.77 \\
\hline Karolinska Univ. & $4,153.5$ & $3,164.3$ & 1.22 & $3,181,873$ & 1.21 & 11.22 & 12.22 \\
\hline Stockholm Univ. & $2,091.0$ & $1,934.7$ & 1.22 & $1,778,460$ & 1.33 & 9.21 & 11.00 \\
\hline Umeå Univ. & $1,622.0$ & $1,411.3$ & 1.10 & $1,613,982$ & 0.96 & 8.42 & 7.28 \\
\hline SLU Swedish Univ. Agr. Sci. & $1,571.0$ & $1,316.9$ & 1.18 & $1,238,255$ & 0.95 & 7.49 & 6.30 \\
\hline KTH - Royal Inst. Technol. & $2,482.5$ & $1,990.0$ & 1.05 & $1,740,250$ & 1.21 & 6.22 & 6.74 \\
\hline Linköping Univ. & $1,588.5$ & $1,423.0$ & 1.00 & $1,262,500$ & 1.12 & 5.49 & 5.54 \\
\hline Chalmers & $1,767.5$ & $1,388.5$ & 1.16 & $1,407,362$ & 1.14 & 3.90 & 4.01 \\
\hline Luleå Univ. Technol. & 416.5 & 370.0 & 0.92 & 603,457 & 0.56 & 2.36 & 1.20 \\
\hline Mid Sweden Univ. & 218.0 & 214.5 & 0.85 & 275,331 & 0.66 & 1.54 & 0.92 \\
\hline Örebro Univ. & 213.0 & 220.2 & 1.09 & 266,006 & 0.90 & 1.59 & 1.29 \\
\hline Karlstad Univ. & 199.5 & 188.3 & 0.85 & 267,767 & 0.60 & 1.51 & 0.81 \\
\hline Växjö Univ. & 135.5 & 140.7 & 0.78 & 210,955 & 0.52 & 1.39 & 0.65 \\
\hline Total & $26,880.5$ & 22,819 & & $22,509,511$ & & 100 & 100 \\
\hline
\end{tabular}

is stable over time this does not create a problem but when a university grows over time, which is the case for the new regional universities in Örebro, Karlstad, Mid-Sweden and Växjö, it is not fair to relate their output, which stems from scarce resources in 20002002, to input in 2007 or 2008.

The following column, E, contains the efficiency of the universities. This is calculated from the output-input relation. Then we use the output-input ratio to calculate the direct governmental funding that ought to be distributed to the universities (column $F$ is the former distribution and column $G$ the new).

Five per cent of the total floor funding is to be reallocated according to publications/citations. Another $5 \%$ is to be redistributed according to external funding, which is a considerable (approximately $60 \%)$ part of the total income.

Looking more closely at the result for 2009 we find that with the $5 \%$ reallocation of direct funding (column F) there is 600 MSEK (= $€ 60$ million) available for redistribution.

Furthermore, there is a new grant from the government of about the same size. Comparing columns $G$ and $F$ we find that there are winners and losers due to performance in relation to historical funding patterns. One group of large universities receives a considerable increase (Stockholm, Uppsala, Lund, Karolinska and KTH - the Royal Institute of Technology).

While Chalmers and Linkoping have a stable situation, some of the larger universities have to meet a significant decrease (Gothenburg, Umea and the Swedish Agricultural University - SLU).

Former university colleges, the so-called new universities, will receive substantially smaller shares of the yearly allocations.

\section{Reality check of field-adjusted production}

One of the main doubts concerning the FAP model is whether it is possible to account for publications in all areas even if the coverage in Web of Science is fairly low. Computer science, humanities and soft social sciences are areas where we know that there are coverage problems and that publication is hidden in a Web of Science-based analysis (Moed, 2005). The answer to that type of question is that the method works with high precision at the university level. We consider field coverage as icebergs (Schubert and Braun, 1992); what we see above the water line makes it possible to compute the total activities whether these are in books or institutional reports. The proof is in the pudding and, therefore, we will execute empirical investigations using databases which aim at covering all types of publications from researchers. These we find at Swedish and Norwegian universities and they contain publications of different types (journal articles, books, chapters in books, etc.).

Since 2006 Norway implements a performance model based on output data. These data build on a combination of self-reported and database-generated

One of the main doubts concerning the
field-adjusted production model is
whether it is possible to account for
publications in all areas even if the
coverage in Web of Science is fairly
low

One of the main doubts concerning the field-adjusted production model is whether it is possible to account for publications in all areas even if the low 
'scholarly' publications. According to the architect of the Norwegian system it is built on a:

simple model for delimiting, weighting and counting publications in a way that balances between field-specific publication patterns. (Sivertsen, 2008)

Fractionalizing publications is at the heart of this balancing effect. Furthermore, the system includes incentives to publish in the most prestigious journals or publishing houses. There are two layers, level 1 and level 2, with different points, for example, while a journal article at level 2 gives 3 points and a book 8 points, an article at level 1 equals 1 point and a book 5 points.

The Norwegian publication model acknowledges only some categories of academic publications such as articles in journals, chapters in books and books. Each journal and publishing house has to be approved by a national committee. A problem is that dissertations, textbooks, instruction books, seminar papers, institutional reports and patents are not considered as original academic research in the Norwegian model (Sivertsen, 2006). Another problem is the accuracy of the data. In a double check performed on publications in the 2006 round, it was found that half the publications points credited to a university were wrong, mainly due to false reporting of textbooks as books, and there were also several other forms of error (Hernes, 2007).

\section{Using Swedish publication databases}

In this section the Norwegian model is used for counting publication points from the Swedish universities and the result of the comparison between models is shown. We had the ambition of using publication databases from all Swedish universities, but ended up with data from six of the largest Swedish universities (Umeå, Uppsala, Swedish Univ. Agr. Science, Linköping, Chalmers and Gothenburg). These universities account for about half of the output production from Swedish universities.

When we applied the Norwegian model we did not have the time to check whether textbooks, etc. had been reported as academic publishing. The purpose of the databases is not to distinguish between different types of publications and there are several systems for classification in operation at these universities. It should be kept in mind that systematic validation or control has not been executed and, therefore, this reality-check is more a test of whether the different systems create very different results at the university level. Also, it should be pointed out that we have to restrict the empirical investigation to a two-year period (2005-2006) as some of the publication databases have only recently been established. Our impression is that the FAP model produces more stable data on the basis of four-year periods, but we decided to use the self-reported data also for the adjusted data analysis in order to obtain comparable data.

First, a matter of caution: we have noticed an under-coverage of actual publications of at least $30 \%$ in these databases. This was found by validating the local databases using the Web of Science data. There are, of course, large variations in this respect, but in general local Swedish databases are incomplete and not reliable for more precise investigations. Still, we intend to show the results of a comparison between the Norwegian and Swedish models for performance-based funding to universities. The under-reporting is, of course, the same for both models and this problem will not in itself create any differences.

The main impression of Table 3 is a surprising similarity between the models. Although we have not corrected for any obvious errors in the databases we find that the FAP model pictures the publication performance at the same level as the Norwegian model. The Swedish model has the advantage of making possible the use of actual citations (received citations, not expected citations) in the performance model. This latter procedure credits Uppsala, Umeå and the Swedish Agricultural University a higher proportion of the total publication points due to their higher citation rates (Table 2, column C).

This investigation shows that the FAP model is a potent alternative to the Norwegian accounting and collecting of all publications. FAP values follow the Web of Science (or Scopus) databases and are easy to compute. In order to establish the Nordic database we used less than four person-months.

\section{Using Norwegian databases}

The Norwegian FRIDA database is a more complete and probably more processed database than the Swedish databases. In order to validate the results from the Swedish survey we will use data from four universities collected from the Norwegian databases FRIDA and DBH (<http://dbh.nsd.uib.no/pub/>) in this section.

Table 3. Comparison of the Norwegian and Swedish models for six Swedish universities

\begin{tabular}{lccc}
\hline University & $\begin{array}{c}\text { A. } \\
\text { PubPoints } \\
\text { (Norwegian) }\end{array}$ & $\begin{array}{c}\text { B. } \\
\text { FAP } \\
\text { (Swedish) }\end{array}$ & $\begin{array}{c}\text { C. } \\
\text { FAP*NCSf }\end{array}$ \\
Chalmers & $10.2 \%$ & $10.4 \%$ & $10.4 \%$ \\
Gothenburg & $22.2 \%$ & $21.2 \%$ & $19.8 \%$ \\
Linköping & $16.7 \%$ & $16.5 \%$ & $14.7 \%$ \\
Swedish Agr. Sci. & $8.3 \%$ & $10.7 \%$ & $11.7 \%$ \\
Umeå & $11.8 \%$ & $11.4 \%$ & $12.1 \%$ \\
Uppsala & $30.8 \%$ & $29.7 \%$ & $31.4 \%$ \\
& $100 \%$ & $100 \%$ & $100 \%$ \\
\hline
\end{tabular}

Source: Publications databases at each university

Note: $\quad$ NCSf is field-normalized citation score 
Table 4. Comparison of models for four Norwegian universities

\begin{tabular}{llrrrr}
\hline & Oslo & Bergen & Tromso & Trondheim \\
& & & & & \\
PubPoints & $44.5 \%$ & $22.8 \%$ & $8.9 \%$ & $23.9 \%$ & $100 \%$ \\
FAP & $41.4 \%$ & $25.7 \%$ & $9.2 \%$ & $23.7 \%$ & $100 \%$ \\
FAP*NCSf & $42.9 \%$ & $25.6 \%$ & $8.5 \%$ & $23.0 \%$ & $100 \%$ \\
$\begin{array}{l}\text { Research } \\
\text { Income }\end{array}$ & $41.0 \%$ & $22.9 \%$ & $11.1 \%$ & $25.0 \%$ & $100 \%$ \\
$\begin{array}{l}\text { Personnel } \\
\text { FTE }\end{array}$ & $41.9 \%$ & $22.4 \%$ & $10.7 \%$ & $25.0 \%$ & $100 \%$ \\
\hline Source: & FRIDA database; data from NIFU/STEP for income and \\
\multicolumn{4}{l}{ personnel }
\end{tabular}

Output indicators are the same as in the former investigation on Swedish universities. We compute:

1. Norwegian publication points;

2. Swedish FAP values;

3. Total resources for research; and

4. Personnel (FTE full-time equivalents).

Full information is given in Table 4. Again we find that there are only small variations between the models (rows 1 and 2 in Table 4). Oslo University receives more points from the Norwegian model while the FAP model gives points to Bergen. Why this is the case is not easy to elucidate, but there might be high production figures from the humanities and theology faculties at Oslo University.

In Figure 1 we use both performance models over research disciplines (faculty areas) for the four Norwegian universities. Here, we find that both models seem to describe publication frequencies over areas of science fairly well. However, the Swedish model is a bit more efficient if we relate figures to percentage of research funding or percentage of research personnel. The Norwegian performance model seems to over-estimate the production from humanities and social sciences. At the same time medicine and engineering sciences seem to be under-estimated. This is one of the core problems with the Norwegian model. In our understanding the local publication channels used within the humanities (and soft social sciences) are in many cases credited with level 2 although disputable and open to criticism. This might lead to a deadlock for Norwegian humanities if the incentive for international publication is broken.

It should be recognized that incentive systems are not the same as evaluation systems where there is need for complete information of research activities. Therefore, if the system is organized according to the actual publication channels in use today this might hinder a change towards international publications channels.

One feature of the Norwegian data is that we can relate performance to research income per faculty area. We find that publication points per million NOK are higher for humanities and social science but lower for medicine and engineering. Natural science seems to fall in between. Obviously, there is more money available for technical and medical research than for other types of research.

Considerations of this type lie behind the decision by the Swedish Government to put factors onto the figures for the two indicators: publication/citations and external funding. Humanities and social science receive a factor of two, medicine and engineering science a factor one, and natural science a factor 1.5.

These factors are put on both publications and external funding and were politically motivated. They might be the result of an unfortunate error in the method for computations. Instead of setting the total performance in relation to total research income, the government has related performance to size of floor funding. As a consequence, the 2009 Swedish Research and Innovation Bill to a large extent balances the size of external funding rather than corrects for differences in publication performance.

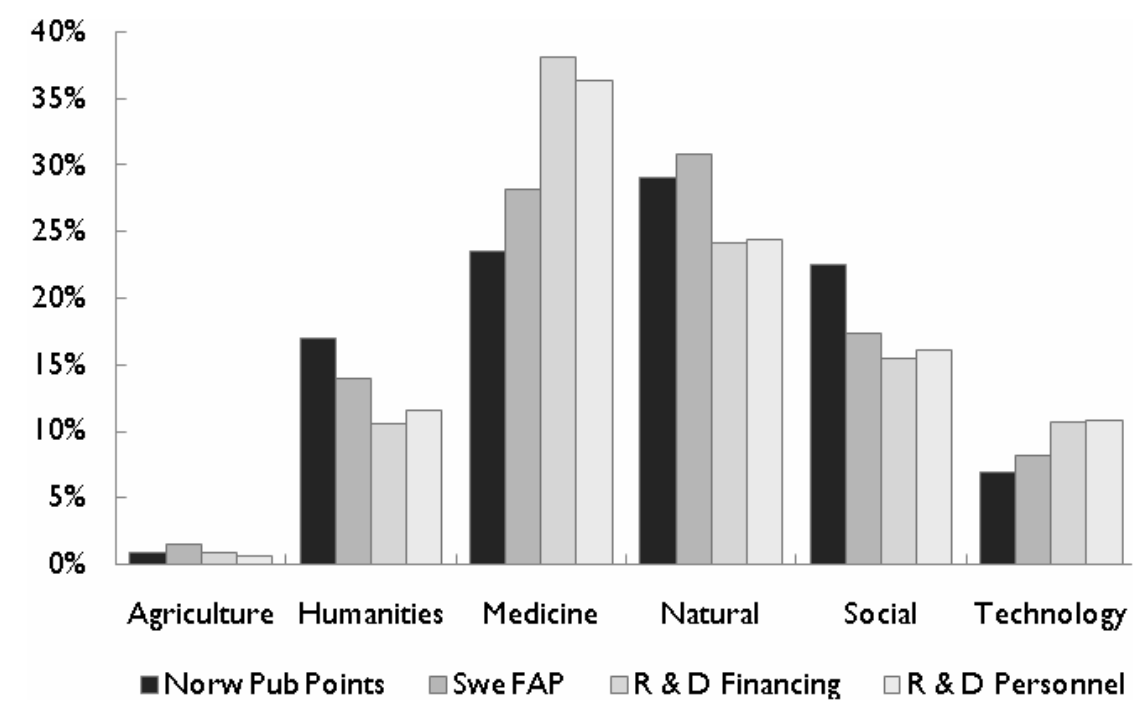

Figure 1. Norwegian and Swedish publication counts related to input indicators 


\section{Conclusion and discussion}

The field-adjusted production based on the FAP model is a viable alternative for national schemes of performance-related funding. First and foremost the model can be evaluated according to these parameters:

\section{- Cost efficiency}

- Validation of data

- Citation counts

- Normative direction.

As indicated above, the labor costs are very limited. Diffusion of the model outside of the Nordic countries will be dependent on whether a European database with unified data can be established. There might be a need for different geographical versions of the model, for example, a German-speaking group of countries (Germany, Austria): an Englishspeaking group (UK, the Netherlands), a Romance language-speaking group (France, Italy, Spain).

Full names are now included in the Web of Science and a connection between name and address is coming. Accordingly, it should be possible to create a unified author database for each of these groups of countries in the near future. Eventually, this could be an exercise for the European Union.

Validation of data is not needed, although possible, in the FAP model but, of course, the unification of addresses is a prerequisite for putting the model into use. There are no self-reporting procedures and no possibilities of discussions of whether or not a publication meets the requirements of the model. This function is performed by the Thomson Reuters selection of journals.

The main advantage of the FAP model is that actual citations are taken into account. Compared to the Norwegian model, which gives a higher level for $20 \%$ of the best journals and publishing houses, the actual performance of a group is additionally measured with citations. Normalized citations are usually considered a more reliable indicator than to which journals a group has submitted their papers. To some extent, the Norwegian model leans on the journal impact factor and would have to meet the well-known type of criticism (Seglen, 1994). Actually there are several areas where the citation performance of Norwegian papers in level 1 is better than the performance in level 2 (Sandström, forthcoming).

Finally, the normative direction in the two models should be compared. Incentives in the Norwegian model are not really clear-cut. An analysis performed by Norwegian economists showed that there are several possible interpretations: While the official version is to stimulate level 2 publications (and publishing in general), there might be a strong incentive for mass publication in level 1 journals and books (Gabrielsen et al, 2007). In the Swedish FAP model there can be no doubt about the incentives. A university that wants a higher share of the resources should preferably try to strengthen their levels of normalized citations and practise a more selective publication strategy. Salami-slicing of papers will have a negative impact on the citation rate. Authors should try to find their audiences instead of finding the journals with the highest impact. In some areas, such as humanities and soft social sciences, there is a clear incentive for more publications.

The application of the FAP model to Swedish universities shows that the reallocation effect can be quite substantial. The future will show how these effects will be interpreted and the type of action taken by the universities. Just as the Norwegian model has met critical debate there are features of the Swedish model that should be discussed. First, the model has its main drawback in the lack of transparency. Second, there is a problem using FAP figures and citations with the humanities and soft social sciences. Third, the geographical delineation, Nordic, European or other, could be a topic for discussion and methodological work.

\section{Note}

1. The classification of journals is available at <http://www. forskningspolitik.se/DataFileD.asp?FileID=4>.

\section{References}

Boyack, K W 2009. Using detailed maps of science to identify potential collaborations. Scientometrics (forthcoming). DOI: 10.1007/s11192-009-0402-6.

Boyack, K W and R Klavans 2006. Identifying a better measure of relatedness for mapping science. Journal of the American Society for Information Science and Technology, 57(2), 251-263.

Braun, T, W Glänzel and A Schubert 1990. Publication productivity: from frequency distributions to scientometric indicators. Journal of Information Science, 16, 37-44.

Buxenbaum, H, F Pivinski and S J Ruberg 1987. Publication rates of pharmaceutical scientists: application of the Waring distribution. Drug Metabolism Reviews, 18(4), 553-571.

CWTS 2008. Leiden Ranking <http://www.socialsciences. leidenuniv.nl/cwts/the-leiden-ranking.jsp>, last accessed 15 August 2008.

Gabrielsen, T S, O M Kaarbøe, K E Lommerud, A E Risa and S Vagstad 2007. Finansieringssystemet for universitets - og høyskolesektoren - teoretiske vurderinger. PM to the Norwegian Ministry of Education, Oslo.

Glänzel, W (1996). The need for standards in bibliometric research and technology. Scientometrics, $35: 167-176$.

Glänzel, W and A Schubert 2003. A new classification scheme of science fields and subfields designed for scientometric evaluation purposes. Scientometrics, 56(3), 357-367.

Glänzel, W, A Schubert and A Telcs 1984. Characterization by truncated moments and its application to Pearson-type distributions. Zeitschrift für Warscheinlichkeitstheorie und verwandte Gebiete, 66,173-183. (Correction: Glänzel, W, A Schubert and A Telcs 1987, 74, 317.)

Hernes, S 2007. Publiseringspoeng og referansekvalitet. Forskerforum, 6/2007 (in Norwegian).

Irwin, Jo 1963. The place of mathematics in medical and biological sciences. Journal of the Royal Statistical Society, Series A, 126, 1-44.

Martin, S, W M Brown and K Boyack (in preparation). DrL: distributed recursive (graph) layout. Journal of Graph Algorithms and Applications.

Narin, F and K S Hamilton 1996. Bibliometric performance measures. Scientometrics, 36(3), 293-310. 
Prop. 2008/09:50 Ett lyft för svensk forskning. (The Research and Innovation Bill 2009-2012).

Rinia, E J, T van Leeuwen, E E W Bruins, H G van Vuren and A F $\mathrm{J}$ van Raan 2002. Measuring knowledge transfer between fields of science. Scientometrics, 54(3), 347-362.

Sandström, $U$ (forthcoming). On journal impact and the Norwegian model. Ms.

Sandström, U and E Sandström 2007. Metrics for academic research: applied to Australian universities 2001-2004. E-prints in Library and Information Science <http://eprints.rclis.org>.

Sandström, U and E Sandström 2008a. Resources for Citations (in Swedish: Resurser för citeringar). Stockholm: National Board for Higher Education.

Sandström, U and E Sandström 2008b. Research Income, Personnel and Publications: Steps towards a Model for Research Productivity. Presentation at PRIME Indicators Conference, Oslo, 28-30 May 2008.

Schubert, A and T Braun 1992. Three scientometric etudes on developing countries as a tribute to Michael Moravcsik. Scientometrics, 23(1), 3-19.

Schubert, A and T Braun 1996. Cross-field normalization of scientometric indicators. Scientometrics, 36, 311-324.

Schubert, A and W Glänzel 1984. A dynamic look at a class of skew distributions: a model with scientometric applications. Scientometrics, 3, 149-167.

Schubert, A and A Telcs 1986. Publication potential - an indicator of scientific strength for cross-national comparison.
Scientometrics, 9(5-6), 231-238.

Schubert, A and A Telcs 1989. Estimation of the publication potential in 50 U.S. states and in the district of Columbia based on the frequency distribution of scientific productivity. Journal of the American Society for Information Science, 40(4), 291-297.

Seglen, P O 1994. Causal relationship between article citedness and journal impact. Journal of the American Society for Information Science, 45, 1-11.

Sivertsen, G 2006. A bibliometric model for performance based budgeting of research institutions. In Book of Abstracts, pp. 133-135, 9th International Science and Technology Indicators Conference, Leuven, Belgium, 7-9 September 2006.

Sivertsen, G 2008. Experiences with a bibliometric model for performance based funding of research institutions. In Book of Abstracts, pp. 126-128, 10th International Conference on Science and Technology Indicators, Vienna, Austria, 17-20 September 2008

SOU, 2007. Resources for Quality (in Swedish: Resurser för kvalitet). Governmental white paper, available at <www. regeringen.se>.

Telcs, A, W Glänzel and A Schubert 1985. Characterization and statistical test using truncated expectations for a class of skew distributions. Mathematical Social Sciences, 10, 169-178.

Van Raan, A F J 1996. Advanced bibliometric methods as quantitative core of peer review based evaluation and foresight exercises. Scientometrics, 36(3), 397-420. 
Copyright of Research Evaluation is the property of Beech Tree Publishing and its content may not be copied or emailed to multiple sites or posted to a listserv without the copyright holder's express written permission. However, users may print, download, or email articles for individual use. 